\title{
Risk of COVID-19 Spread and Mitigation Strategies in Public Transportation Sector
}

\author{
Niloy Saha1, Mohiuddin Quadir², Ranjit P. Godavarthy ${ }^{3 *}$ \\ ${ }^{1}$ Department of Civil and Environmental Engineering, North Dakota State University, Fargo, ND, USA \\ ${ }^{2}$ Department of Coatings and Polymeric Materials, North Dakota State University, Fargo, ND, USA \\ ${ }^{3}$ Transportation and Logistics, North Dakota State University, Fargo, ND, USA \\ Email: niloy.saha@ndsu.edu,mohiuddin.quadir@ndsu.edu, ‘ranjit.godavarthy@ndsu.edu
}

How to cite this paper: Saha, N., Quadir, M. and Godavarthy, R.P. (2021) Risk of COVID-19 Spread and Mitigation Strategies in Public Transportation Sector. Journal of Transportation Technologies, 11, 504518.

https://doi.org/10.4236/jtts.2021.114032

Received: July 20, 2021

Accepted: August 24, 2021

Published: August 27, 2021

Copyright $\odot 2021$ by author(s) and Scientific Research Publishing Inc. This work is licensed under the Creative Commons Attribution International License (CC BY 4.0).

http://creativecommons.org/licenses/by/4.0/

\begin{abstract}
The world is trying to recover from once in the COVID-19 pandemic, which has a higher mortality rate than the common flu. However, the threat of different variants is still affecting us in a different capacity. Several preventive measures have been adopted across the nation and the globe to avoid the spread of this virus, such as lockdown, restricted travel, social distancing guidelines, obligatory face mask use, etc. These activities directly influenced the management of social life, economy, and livelihoods. The effect of COVID-19 on the public transit industry and strategies the transit agencies adapted to continue providing the service during the pandemic has been synthesized in this paper. As a result of the pandemic, public transit ridership decreased by about 70 percent for most agencies compared to pre-pandemic levels. This article also highlights the prevention of COVID-19 spread in the public transit industry using engineering solutions and advanced material science and nanotechnology solutions.
\end{abstract}

\section{Keywords}

COVID-19, Public Transit, Engineering Solution, Advance material Science

\section{Introduction}

In early 2020, a new virus called acute respiratory coronavirus two or SARS-CoV-2 or COVID-19 has caused a global pandemic. As of this writing, the total case toll from the pandemic reached 32 million in the USA, and the death toll has reached more than $573 \mathrm{~K}$ [1] worldwide, the case toll is 152 million, and the death toll is more than 3.19 million [2]. In September 2020, a new mutated version of coronavirus was detected in England; more mutations were later detected 
in South Africa, India and swiftly became the predominantOVID-19 strains in some countries [3]. While COVID-19 vaccinations are actively being administered worldwide, the emergence of new COVID-19 strains is sometimes not shielded effectively by the vaccines currently being administered. Further, a significant percentage of unvaccinated people in the US and worldwide are fueling the spread of new COVID-19 strains among the public.

The public transport system is one of the most affected sectors due to the pandemic. According to the American Public Transportation Association (APTA), public transport ridership declined by $80 \%$ in April 2020 (Figure 1), and the decline was close to $60 \%$ for the rest of the year [4]. The same source also projected that this trend would continue through the third quarter of 2021, and the ridership would begin to rise as the vaccination rate increases.

A rapid decline in Vehicle Miles of Travel (VMT) for public transit in the United States was observed in April 2020. By December 2020, VMT decreased by $74 \%$ compared to 2019 levels [5]. Due to lockdowns in place, most transit riders stopped using public transit because of safety concerns. The global economy crashed, and one-fourth of the US economy went idle during March 2020. The USA's gross domestic product (GDP) decreased 3.5\% in 2020, the largest drop since 1946 [6]. According to the Congressional Research Service [7], the unemployment rate in the United States reached 14\% in April 2020; the rate is 6\% as of February 2021 [8], and it is expected that the US economy will return to the pre-pandemic levels by the second quarter of 2021 [6]. Among many sectors impacted by the pandemic, the public transit sector lost much business and yet has to remain operational for most cases to provide critical lifelines to the public.

This paper aims to document the impact of COVID-19 on the public transit industry, synthesize COVID-19 prevention strategies for public transportation operations, and ways to make public transit ridership safer for all passengers. To do that, this paper will briefly summarize the biology of the COVID-19 virus, and how it spreads inside public transit vehicles. The paper later discusses the

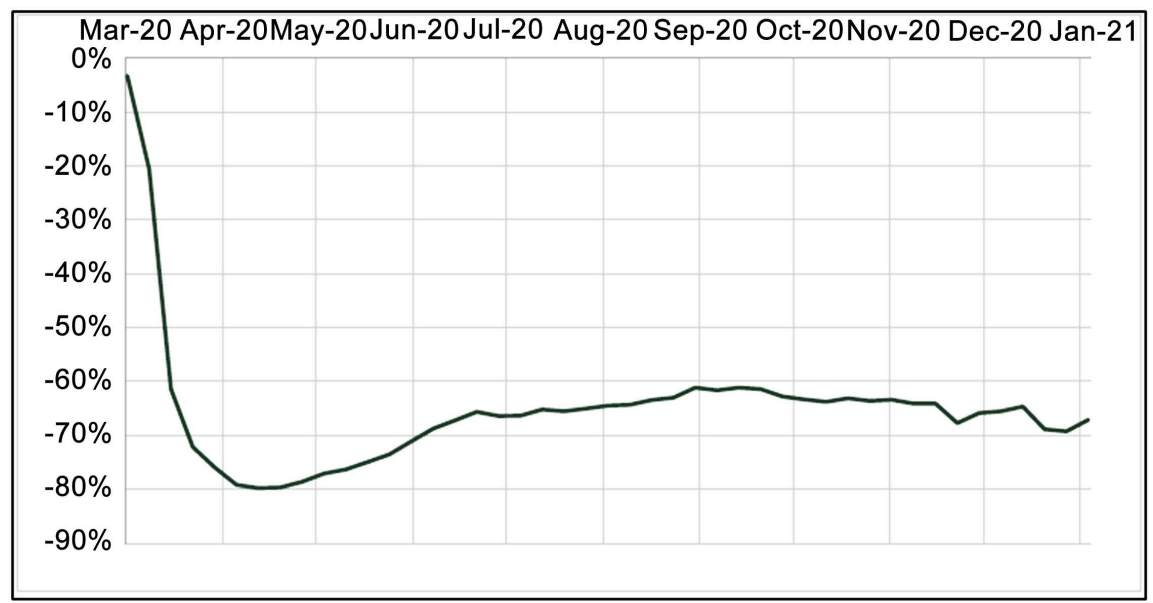

Figure 1. Public transit ridership losses and projection by APTA ridership trends dashboard powered by transit [4]. 
prediction model available to predict the future spread of the virus, followed by the public transit operation strategies and lessons learned from the United States operations and across the world. Finally, the paper will present prevention mechanisms, including engineering solutions, logistics supports, and prevention technologies with advanced material science and nanotechnology.

\section{Background}

\subsection{Mechanism of Spreading in Public Transit}

Public transit vehicles are confined with conducive spaces that lead to the spread of contagious diseases, such as COVID-19, from human to human. Several possible ways to spread the virus include circulation of virus cough, sneezing from infected person to the non-infected person, and spreading through surfaces frequently touched by the public [9]. People sit closely in public transportation settings, which causes a $60 \%$ higher risk of infection than those in the low-risk area [10]; also conclude that this virus can spread in a closed air circulation environment.

It was advised initially to maintain a 6 feet social distance, but this hypothesis does not work while public transit vehicles as the air driven by a fan or vent device will scatter respiratory droplets as much as 6 feet [11]. Case studies of COVID-19 transmission through bus service were observed in a research study where a COVID-19 positive person traveling in a bus has affected 243 close contact persons [12]. The primary reason for contracting the virus among the affected people was transmission via droplets, and few infections were assumed to be due to touching fomites.

The concept of air-conditioning and running ventilation inside buses has provided a perfect atmosphere for aerosol transmission [13]. In eastern China, 24 people were found positive while traveling in an air-conditioned bus service and with a COVID-19 patient [14]. The study concluded detecting this virus as an aerosol transmitted virus inside the controlled environment. While human aerosol spread inside the airtight environment mixing with fresh air, opening doors and window was found the reduction the concentration by almost half [15].

\subsection{Mathematical Analysis and Fluid Model}

Researchers have developed mathematical models and analyses to figure out characteristics of COVID-19 and predictions of the number of people affected.

Saliva droplet distance measurement when a person cough was measured in research [16]. Using the physics of the fluid model, results show that droplet size 1000 micrograms in diameter travel $11.5 \mathrm{ft}$., 750 micrograms diameter cross around $8 \mathrm{ft}$., 30 - 50 micrograms in diameter cross $13-19.5 \mathrm{ft}$. into the air which landed more than 6 feet distance. This paper presents an analytical approach to the continuation of COVID-19 in an efficient way.

A forecast model using a time series approach was developed to predict case 
numbers in the future in another research [17]. The authors used cumulative confirmed deaths and recovered data retrieved from the Center for System Science and Engineering at John Hopkins University to develop the model. Studies indicate a continued rise in the confirmation of COVID-19 cases that remain with significant uncertainty, assuming that the statistics used are accurate and that the future continues to follow the disease trajectory of the past.

The researchers for examining coronaviral propagation developed a simulation-based model. This model uses cellular automatons in two dimensions. $\mathrm{Nu}-$ merical models were conducted in three epidemic countries as Poland, France, and Spain. The observational results suggest a close association between infected individuals' age and mortality levels. The authors have included the death chance system that relies upon the population age structure under study. Also, we examined the connection between the fundamental reproductive number and the direct rate of interaction between people. The findings suggest that one contact every two days leads to an infection in more than three patients. A hybrid intelligent model proposed by researchers simulates the expansion of COVID-19 [18]. Firstly, the impact of government investments, television advertising, medical care, and enforcement on the spread of epidemics was analyzed. Then, a genetic algorithm (GA) optimizes the infection rate, and later the modified disease propagation model susceptible-infected-quarantined-recovered (SIQR) was proposed. To further refine other system model parameters and achieve the best predictive model with control measurements in the SIQR model, long-term memory (LSTM) was incorporated in the model. Simulation findings suggest a strong predictive capacity for the proposed hybrid intelligence algorithm. This paper looks at the best government output on the four dimensions and suggests a hybrid model of LSTM prediction based on the SIQR disease spread model. Through examining new cases and death rates from February 26 to October 13 for Brazil, it is seen that media ads and law enforcement contribute most to reducing the transmission rates.

\subsection{Transit Operation Strategy during Pandemic}

During the $1^{\text {st }}$ wave of the pandemic, several countries went through lockdown for few weeks, which was later extended for few more weeks to bring the COVID-19 pandemic in control. As mentioned before, the public transportation industry is one of the most affected sectors due to the COVID-19 pandemic, and the industry has undergone a financial crisis as their public transit operations were continued, but the demand was very low. A sample survey analysis of some 2500 participants from the Netherlands Mobility Panel demonstrated that the COVID-19 outbreak could lead to systemic changes in travel behavior and the commitment to the operation. Based on the study results, about 80 percent of the people were less involved in activities outside of their homes; the percentage for older adults was much higher. The number of trips was decreased by $55 \%$ from the same time last year, and the distance traveled was reduced by $68 \%$ [19]. 
Another study conducted in New York State found that 72 percent of the survey respondents out of 1000 inhabitants avoided transit over private cars [20].

On the other hand, analysts have anticipated that low-income household members affected by the pandemic will undoubtedly switch to public transit [21]. During this pandemic, transit authorities introduced special services to the health workers to ride to the clinic or health center by extending operating areas. In few areas, transit authority also used their bus service to provide foodstuff, deliver food through app service, pool many supplies into one vehicle to enhance efficiency, and allow drivers to differentiate deliveries from passengers. The overall policy included changing operating hours to further comply with medical timing changes and capping all transit at a capacity of $50 \%$ to better account for social distance for riders on private routes [22]. To keep the public transit industry operational during and after the pandemic, it is necessary to identify promising operational strategies to provide safe rides to the public while operational. This section presents operational strategies adopted by some major public transportation providers in the United States and other countries. Promising lessons learned from various providers will be presented towards the end of the section, which other public transit agencies can adapt to provide safe public transit operations.

Chicago Transit Agency (CTA), one of the major public transit agencies in the United States, has been dramatically impacted by the COVID-19 pandemic. The CTA ridership has seen an $80 \%$ reduction, and the bus ridership has seen much reduced compared to rail systems within the agency [23]. Innovation, versatility, and accountability are the key aspects that CTA believed will assist in the recovery phase from the pandemic. CTA believes that learning and applying the best practices of other transit agencies, continuous review of decisions, integration with other programs, including the sharing of rides and the sharing of bikes, can aid the transit agency and its operations during an outbreak. Figure 2 shows cleaning activities done by CTA during the pandemic. Several steps taken by CTA for conducting the operations during the pandemic are:

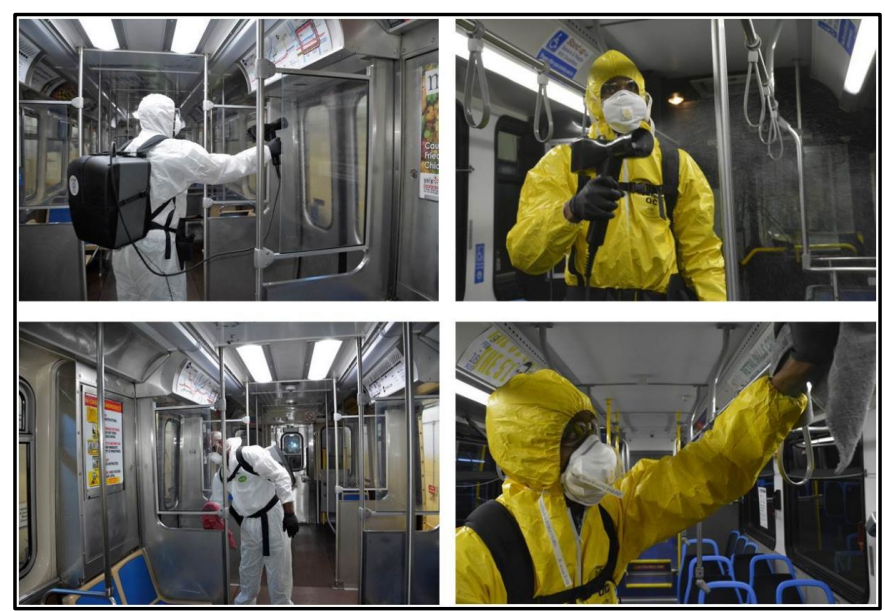

Figure 2. CTA workers using e-sprayers as part of the deep cleaning process [24]. 
- Providing as many as a possible trip number through pandemic and reopening process.

- Capacity reduction to avoid crowds inside the bus.

- Identifying crowded routes and adding additional bus services.

- Maintaining social distance and wearing musk signage in each bus and at stations.

- Proper cleaning before and while in service with extra deep cleaning during nighttime.

- Using electrostatic sprayers for deeper cleans, antimicrobial surface coating, and using UV cleaning technology to continue the cleaning process.

- Distributing free health kits containing a mask, sanitizer, and guidance for proper hygiene tips to the users.

Jacksonville Transportation Authority (JTA) provides public transit services in the city of Jacksonville, Florida. Following the COVID-19 pandemic, JTA transit ridership fell by $75 \%$, which led to a decrease in operations and service frequencies [23]. JTA had installed plexiglass shields for bus operators even before the pandemic peaked in Florida as part of the regaining ridership. Personal protection equipment was also issued for JTA employees (PPE). One crucial decision made by JTA during the pandemic was to postpone the opening of the regional transit center but decided to upgrade the already operational building to promote safe sanitation and social dissociations. Strategies that JTA has adapted to respond to the pandemic include:

- Mandating face covering for all passengers and adapting a $6 \mathrm{ft}$. distance between passengers during the onboarding process. As a result, bus capacity was limited to 20 people.

- To compensate for capacity reduction due to social distancing requirements, a new bus service was added to make more trips.

- Checking temperature for the employees while reporting to the work.

- Enhanced cleaning activities were performed to reduce the risk.

Washington Metropolitan Area Transit Authority (WMATA) is a public transportation agency that provides public transit services in Washington D.C., where one-fifth of the WMATA's workforce has contracted COVID-19 during the pandemic [23]. WMATA has shut down several low-demand public transit stations during the pandemic cut service times [25]. Like CTA, WMATA also argues that learning from peer organizations worldwide would be beneficial for transit operations. WMATA assumes public transportation in a post-COVID world would be critical for safe and sustainable cities. Since March 2020, WMATA has implemented several actions to mitigate the risk of OCIV-19 spread for public transit riders. Below are the strategies adopted by WMATA during various time frames.

- Riders were advised to wash their hands with soap for 20 seconds, wear face masks, and avoid touching the nose and eyes.

- Transit service was reduced for few lines to control the spread. Rail service span was increased to provide service for needed riders. 
- Few metro transit stations were closed to slow the spread. For example, two specific stations were closed to discourage tourists and residents from visiting cherry blossoms.

- Adapted read boarding systemwide for its transit operations.

MATBUS provides public transit services in Fargo, North Dakota. Fargo is a small city compared to the cities described above. While smaller transit agencies in the United States have been adversely affected by the COVID-19 pandemic, findings from MATBUS's transit operations can provide a glimpse to understand how smaller transit agencies adapted their operations to the pandemic. Figure 3 shows the face-covering sign used in Matbus during the pandemic. Several strategies that MATBUS adopted, presented below [26]:

- The mandatory facemask was made for all riders inside the bus, bus station, and nearby a bus station from August 3, 2020. A complimentary mask was kept inside the bus for those who do not wear a mask.

- Fare collection was suspended until March 31, 2021, to avoid close contact between drivers and passengers.

- All routes were operated during the pandemic, and the transit hub was open to the public.

- Vehicle operators were provided proper PPE kits to keep themselves safe.

- Passengers are requested to use the rear door; the front door was dedicated for disabled passengers who need to use the ramp.

- Standard cleaning procedures keep the bus sanitized; plexiglass barriers were installed to have a barrier between the driver and the passengers.

While the above paragraphs summarize the impact of COVID-19 on transit agencies in the United States, transit agencies outside the United States have faced similar challenges. Each of the agencies has adapted strategies to better serve their communities by continuing their operations.

TransLink provides public transit services in Vancouver Metro, Canada. It has seen a $50 \%$ decrease in its sales, and the ridership has fallen pre-ridership up to $30 \%$ [23]. TransLink adopted some specific strategies during the pandemic, and these strategies are summarized below [27]:

- Mandatory facemask for all passengers inside the agency's vehicles and while waiting to board a vehicle.

- Social distancing requirement with marked markers for passengers.

- Making hand sanitizing dispensers available to all passengers at all stations.

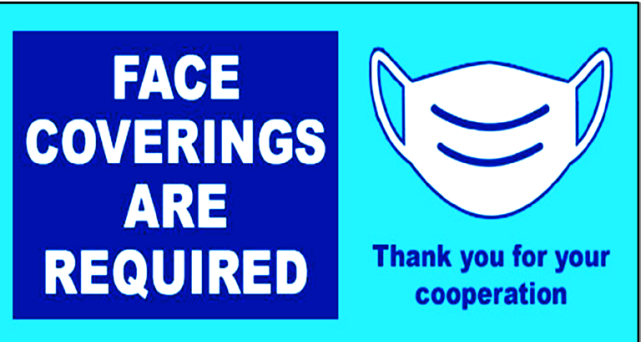

Figure 3. Face covering sign used inside MATBUS vehicles [26]. 
- Implementing contactless payments systems.

- Gather feedback from users during the pandemic to improve the service.

- The dedicated cleaning crew was appointed during the pandemic to enhance cleaning activities and increase cleaning schedules.

Transport for London (TfL) is a UK governmental department, and the agency provides public transportation services to the Greater London area. Residents of London were asked to stop using public transportation unless it is necessary. During the pandemic, TfL worked on consumer confidence rebuilding initiatives. The COVID-19 pandemic was responsible for the loss of $90 \%$ of TfL sales [23]. Figure 4 shows the cleaning activity done by the TFL authority during the pandemic. The strategies TfL adapted to mitigate the spread of the COVID-19 virus include [28]:

- Requesting riders to use facemasks, wash hands, maintain social distance.

- Adopting contactless payment methods.

- Using UV technologies for cleaning.

- Implement one-way passenger flow, safety screening for the drivers, and new signage/poster/stickers installation.

Based on the strategies implemented by various transit agencies in the United States and across the world, some of the promising strategies that were consistent among most agencies include mandating facemask in regions that still have higher COVID-19 cases, maintaining plexiglass barriers between drivers and passengers, encouraging one-way passengers flow, and adjusting service frequency and service span based on the route's characteristics. These strategies have helped all the public transit agencies mentioned in the article to provide safer trips, and the lessons learned from these initial implementations can benefit transit agencies looking for guidance to operate during the pandemic and beyond safely.

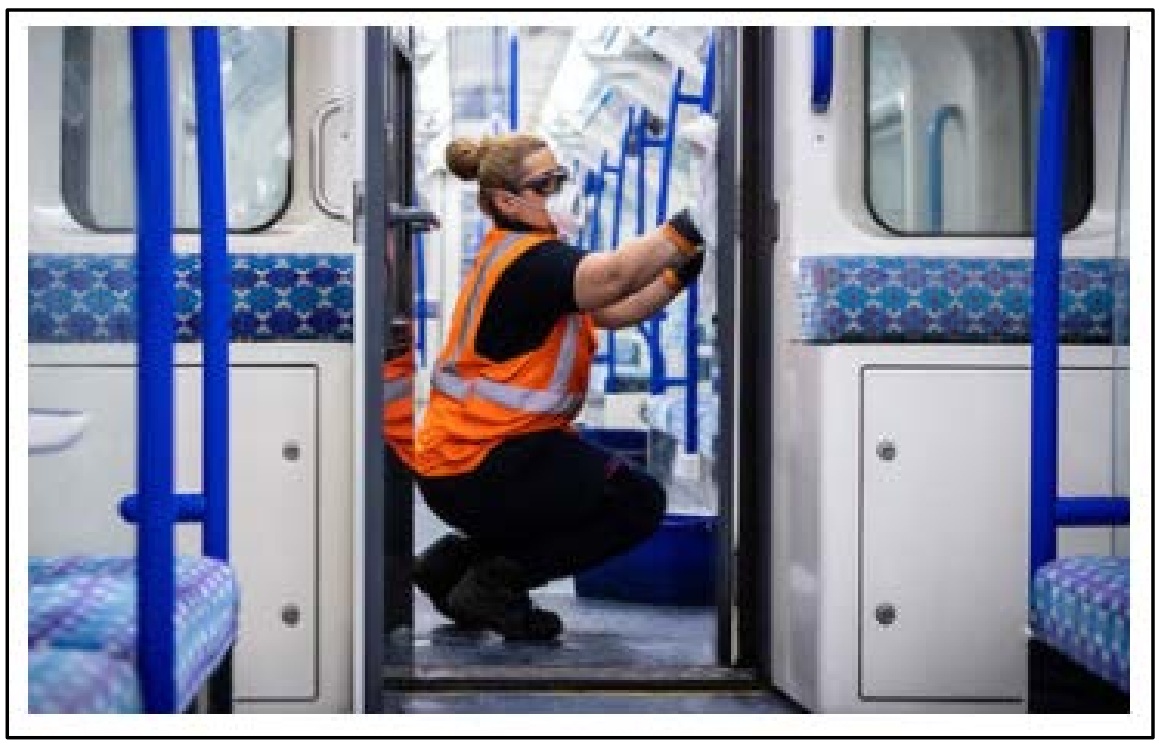

Figure 4. Routine cleaning activity to sanitize public transit fleet in London [28]. 


\section{Prevention of Spread of the Causative Agent}

This paper presents possible short-term and long-term virus (COVID-19 or another regular flu virus) spread prevention methods. While the COVID-19 cases are in decline in the United States and some other countries, it is still important to operate safe public transit services in the future so riders can feel comfortable. The prevention methods in this paper are classified as engineering applications, logistic applications, and chemical prevention methods.

\subsection{Engineering Prevention}

Most buses are regularly air-conditioned these days. However, if the air-conditioning system cannot be modified to provide fresh air, filtering the virus particles such as COVID-19, COVID-19 virus, and other viruses can spread inside public transit vehicles. It is important to regulate bus air flows to optimize fresh air ventilation by adding sterilization systems and advanced filters for public transit vehicles [29]. According to Colorado Springs Mountain Metro Transit and Colorado school district 11, opening windows and using available bus fans have been shown to minimize the chance of COVID-19 spread by 84 percent. Further, it was found that bus HVAC systems removed airborne particulates within $4 \mathrm{mi}-$ nutes using MERV-13 air filters [30]. Using HEPA, air filters were found to remove $99.97 \%$ dust pollen and airborne particles of 0.3-micrometer size [31]. If controlling the airflow is the potential strategy for any agency to prevent the spread of the COVID-19 virus, it will be wise to create positive pressure (a positive pressure room has higher air pressure than the surrounding environment) inside the transit vehicle to generate better air filtration system [32].

\subsection{Prevention Technologies Using Advanced Materials Science and Nanotechnology}

With the advent of materials science, research groups worldwide are developing smarter prevention methods against COVID-19. Many of these technologies harness the principles of nanotechnology. As a relatively nascent technology, the nanoscopic intervention of matter has already revolutionized the fields of medicine, diagnostics, communication, and agriculture. The principal workhorse of nanotechnology is nanomaterials, which can further be classified as hard (inorganic materials-based) or soft (organic compound-derived) nanomaterials, or a combination of both [33]. On an overarching note, nanotechnology involves designing and developing nanomaterials and nanodevices with at least one of the dimensions less than $100 \mathrm{~nm}$. However, many soft nanoparticles, such as macro-micelles (aggregate of block copolymers) or polymersomes (capsular assembly of polymers), might demonstrate a more than $100 \mathrm{~nm}$ hydrodynamic diameter. Such dimensional similarity of COVID 19 virus (approximately $300 \mathrm{~nm}$ in diameters), nanoscale principles can be utilized to recognize, entrap, filter, or efficiently kill the pathogen when combined with other physical or Physico-chemical methods as described earlier. This new arsenal of therapeutic tech- 
nology has altered the trajectory of our battle against COVID-19 and set us on a winning path against this deadly pathogen. For example, the targetability and deliverability of antiviral drugs, including those obtained from natural sources [34] [35] [36] have been augmented using nanoformulations. In many instances, such augmentation of therapeutic efficiency is tightly connected to the ability of nanomaterials to improve the pharmacokinetic and dynamic properties of the antivirals. The two major vaccine candidates approved by the FDA employ nanosystems in liposomes and lipid nanoparticles [37]. The incorporation of nanoparticles into vaccines develops antigen stability, thereby improving the vaccine's functional efficiency. One of the transformative changes introduced in the combat against COVID-19 is nanoscale biosensors to detect the virus in body fluids, including blood, with high sensitivity and selectivity [38] [39]. The abovementioned therapeutic innovations against COVID-19 will significantly improve passenger safety in transportation settings as an increasing number of commuters will be effectively vaccinated and herd immunity is developed. However, since prevention is better than cure, the transportation network can rely on therapeutic innovations and focus on prevention measures that can mitigate or even suppress the further spread of the disease.

Several research groups across the nation have been actively pursuing this overarching goal, for which both micro and nanoscale technologies have been used as primary tools. For example, the effort by Pacific North West National Laboratory (PNNL) has developed a micro-aerosol disinfecting system that can battle against COVID-19

(https://www.pnnl.gov/micro-aerosol-disinfecting-system-aides-battle-against-c oronavirus). The technology utilizes an organic liquid disinfectant spray via a micro-aerosol generator. The liquid disinfectant is an electrochemically activated solution (EAS) of common sodium chloride salt in water. This solution has significant cleaning and sanitizing properties yet is biocompatible and non-corrosive. Termed as "Paerosol" technology, this liquid disinfectant is converted to dry, microscopic aerosol (under $1 \mu \mathrm{m}$ aerosolized particles of reactive oxidative species) for quick diffusion throughout space.

Such aerosolization technology can remove $99.999 \%$ bacteria, virus, and mold spores residing in hard-to-reach spots and surfaces in a time-dependent fashion. Technology as Paerosol, currently licensed by NanoPure, has been used by the Florida State Firefighters Association (FSFA) to contain COVID-19 virus. In addition to such translational technologies, many research reports have been published over the last year illustrating the feasibility of using surfaces with self-cleaning properties [40]. These functional surfaces can either present antimicrobial effects or release active disinfectants for long-term protection against microorganisms. The later function of active surfaces are particularly as in these systems; the surface can be engineered in such a way that the antimicrobial agent will only be released by the presence of certain physicochemical factors, such as $\mathrm{pH}$ or $\mathrm{pO}$, or by inducing photothermal, electrochemical, electrothermal or photocatalytic 
modulation [41] [42]. Such on-demand activation of antimicrobial agents from surfaces can be introduced into transportation modules for in-service cleaning and disinfection of surfaces. Metallic nanoparticles, such as zinc (Zn), silver $(\mathrm{Ag})$, or titanium (Ti) in their oxide forms, have traditionally been used for their antimicrobial properties. In the wake of the COVID-19 viral surge, the use of these elements has been reinvigorated [43] [44]. As reported by Vaze et al., other interesting disinfection strategies illustrate the use of nano-disinfectants based on engineered water nanostructures (EWNS). These structures are created via electrospray and aqueous suspension ionization of active ingredients [45]. These systems were found to be effective again H1N1 influenza infection. Using such innovative nanotechnology-powered approaches, active disinfectant molecules, such as hydrogen peroxide $\mathrm{H}_{2} \mathrm{O}_{2}$, can also be minimized, which is often beneficial for protecting the surface texture and coatings of vehicles. A critical aspect of viral spread via commute is passenger-to-passenger contact. Although various engineering controls (such as airflow, surface decontamination, social distancing) might reduce the risk, the use of personal protective equipment (PPE) in the form of an efficient face mask is most likely the best option. According to the United States Centers for Disease Control and Prevention (CDC), the major contributing factor that has been identified for the COVID-19 spread is the close contact (person-to-person) and respiratory droplets produced by infected persons [86 BM]. Personal protective equipment, such as a face mask, can protect the passenger from this mode of viral spread. Nanotechnology and materials science can improve the efficiency of the facemask to trap and kill COVID-19 pathogen.

Using the principles of nanotechnology, efficient facemasks with user compliance and pathogen protection can be fabricated [46] [47] [48]. Incorporating enhanced hydrophobicity and antimicrobial capacity without affecting PPE's (such as facemask) compatibility and comfort can provide augmented protection against the virus. Such increment of hydrophobicity can be achieved by using hydrophobic nanoparticles, nanowhiskers, or polymeric surfactants that can alter the surface properties. This approach aims to alter the attachment events of respiratory droplets on surfaces, thereby prevent the growth of COVID-19 pathogen on facemasks [49] [50]. Biocides, such as ammonium or quaternary phosphonium salts, polymers, or peptides organized at the nanoscale, can destroy pathogen species via oxidation [51].

\section{Conclusions}

This paper synthesizes COVID-19 pandemic impact on the public transit industry in the United States and across the globe and describing especially how public transit services have served as essential service during the pandemic for the transit-dependent population to get to their destinations, how the public transit industry has adapted to continue providing service during the pandemic and provided recommendations on providing safe transit operations for future. Ad- 
dressed in detail the intensity of COVID-19 viruses worldwide directly affecting human health, particularly in transportation. This review aims to determine how this virus affected the transport section in terms of riding, total journey number, transit mechanism, and pandemic strategy and providing a solution to recover. The pandemic gradually decreased the number of passengers. Lessons learned from transit agencies operational during the pandemic, solutions from the engineering point of view, and advanced material science and nanotechnology can inform transit agencies in the United States and worldwide to provide safer public transit operations as many countries are still a long way getting their population vaccinated. This unreliable state has limited the production of income, the unemployment of many. However, it demands the recovery of this era by restoring the trust of the protected atmosphere utilizing a short and longer-term prevention system for travelers. A systemic preventive measurement of technical, logistical, and nano-technical benefits has been addressed. These tests have scientifically shown that they promise the eradication of viruses in different trials.

The future recommendation requires a further study on the correct assessment of human mobility and social distancing. The study was often carried out in static circumstances, but this social gap could vary in dynamic conditions. In addition, an adequate annual budget for protective measures should be planned. The United States government has now begun vaccinating most of the population, but many individuals are still non-vaccinated. Transit authorities should take preventive measures to return a precautionary atmosphere as quickly as practicable to maintain the health risk at the lowest level while offering optimal safety advantages.

\section{Conflicts of Interest}

The authors declare no conflicts of interest regarding the publication of this paper.

\section{References}

[1] CDC (2021) COVID Data Tracker. https://covid.cdc.gov/covid-data-tracker

[2] Hopkins, J. (2021) COVID-19 Dashboard by the Center for Systems Science and Engineering (CSSE) at Johns Hopkins. https://coronavirus.jhu.edu/map.html

[3] Bollinger, R. and Ray, S. (2021) John Hopkins Medicine Health. https://www.hopkinsmedicine.org/health/conditions-and-diseases/coronavirus/a-ne w-strain-of-coronavirus-what-you-should-know

[4] APTA (2021) A New Way to Track Changes in Ridership. https://transitapp.com/APTA

[5] Thompson, A. (2020, October) How Work-from-Home Affects 2020's Vehicle Miles Traveled Statistics.

https://www.streetlightdata.com/analyzing-2020-vehicle-miles-traveled-statistics/?t ype $=$ blog

[6] Mutikani, L. (2021, January 27) COVID-19 Savages U.S. Economy, 2020 Performance 
Worst in 74 Years.

https://www.reuters.com/article/us-usa-economy/COVID-19-savages-u-s-economy -2020-performance-worst-in-74-years-idUSKBN29X0I8

[7] Falk, G., Carter, J.A., Nicchitta, I.A., Nyhof, E.C. and Romero, P.D. (2021) Unemployment Rates during the COVID-19 Pandemic: In Brief. Congressional Research Service.

[8] BLS (2021) The Employment Situation-February 2021. UD Department of Labor.

[9] BBC (2020) Coronavirus: What's the Risk on Transport? https://www.bbc.com/news/health-51736185

[10] Shen, Y., Dong, H., Wang, Z. and Sun, Z. (2020) Community Outbreak Investigation of SARS_CoV-2 Transmission among BUS Riders in Eastern China. JAMA Internal Medicine, 180, 1665-1671. https://doi.org/10.1001/jamainternmed.2020.5225

[11] Dhaniyala, S. and Erath, B. (2021, January) How to Safe with a Fast-Spreading New Corona Virus Variant on the Loose. The Conversation.

[12] Luo, K., Lei, Z., Xiao, S., Rui, J., Yang, H. and Jing, X. (2020) Transmission of SARS-CoV-2 in Public Transportation Vehicle: A Case Study in Hunan Province, China. Open Forum Infectious Diseases, 7, ofaa430. https://doi.org/10.1093/ofid/ofaa430

[13] Smieszek, T., Lazzari, G. and Salathe, M. (2019) Assessing the Dynamics and Control of Droplet- and Aerosol-Transmitted Influenza Using an Indoor Positioning System. Scientific Reports, 9, Article No. 2185. https://doi.org/10.1038/s41598-019-38825-y

[14] Shen, Y., Li, C., Dong, H., Wang, Z., Martinez, L. and Sun, Z. (2020) Community Outbreak Investigation of SARS-CoV-2 Transmission among Bus Riders in Eastern China. American Medical Association, Chicago. https://doi.org/10.1001/jamainternmed.2020.8570

[15] Zhang, Z., Han, T., Yoo, K.H., Capecelatro, J., Boehman, A.L. and Maki, K. (2021) Disease Transmission through Expiratory Aerosol on an Urban Bus. Physics of Fluid, 33, Article ID: 015116. https://doi.org/10.1063/5.0037452

[16] Renzi, E. and Clarke, A. (2020) Life of a Droplet: Buoyant Vortex Dynamics Drives the Fate of Micro-Particle Expiratory Ejecta. Physics of Fluid, 32, Article ID: 123301. https://doi.org/10.1063/5.0032591

[17] Petropoulos, F. and Makridakis, S. (2020) Forecasting the Novel Coronavirus COVID-19. PLoS ONE, 15, e0231236. https://doi.org/10.1371/journal.pone.0231236

[18] Zhang, G. and Liu, X. (2021) Prediction and Control of COVID-19 Spreading Based on a Hybrid Intelligent Model. PLOS ONE, 16, e0246360.

https://doi.org/10.1371/journal.pone.0246360

[19] Haas, M.D., Faber, R. and Hamersma, M. (2020) How COVID-19 and the Dutch "Intelligent Lockdown" Change Activities, Work and Travel Behavior: Evidence from Longitudinal Data in the Netherlands. Transportation Research Interdisciplinary Perspectives, 6, Article ID: 100150. https://doi.org/10.1016/j.trip.2020.100150

[20] Taylor, E. (2020, May 14) How Will COVID-19 Impact New York Travel and Tourism in 2020 ?

https://www.driveresearch.com/market-research-company-blog/how-will-COVID19-impact-new-york-travel-and-tourism-in-2020

[21] Taylor, B. and Wasserman, J. (2020) For the Press: Transportation, Coronavirus, and COVID-19.

https://www.its.ucla.edu/for-the-press/transportation-coronavirus-covid19

[22] CUTR (2020) Impact of COVID-19 on Travel Behavior and Shared Mobility Sys- 
tems. USF Center for Urban Transportation Research, Tampa.

[23] NUTC (2020) The Vital Role of Public Transportation in Reopening Our Cities.

[24] CTA (2021) Returning to CTA: What You Should Know. https://www.transitchicago.com/coronavirus

[25] WMATA (2020, August 17) Metro and COVID-19: Steps We've Taken. https://www.wmata.com/service/covid19/COVID-19.cfm

[26] Matbus (2021) MATBUS COVID-19 Response. http://matbus.com/news-events/COVID-19-response\#: :text=Current\%20MATBU S\%20Service,notice\%20before\%20resuming\%20fare\%20collection

[27] TransLink (2021) What Does Transit Look like Right Now? https://www.translink.ca/rider-guide/coronavirus-precautions

[28] TfL (2021) Safer Travel Guidance. https://tfl.gov.uk/campaign/safer-travel-guidance?intcmp $=63123$

[29] Gurley, G. (2020) Reducing Risks in the Air on Buses. https://prospect.org/coronavirus/reducing-risks-in-the-air-on-buses

[30] MITRE (2020) Face Masks, Open Windows on Buses Reduce Potentially Infectious Particles in the Air.

https://www.newswise.com/coronavirus/face-masks-open-windows-on-buses-reduc e-potentially-infectious-particles-in-the-air

[31] EPA (2021) Indoor Air Quality (IAQ). https://www.epa.gov/indoor-air-quality-iaq/what-hepa-filter-1

[32] Marco, J.D. (2020) COVID-19 and Negative Pressure Rooms in Hospitals. https://www.chthealthcare.com/blog/negative-pressure-rooms

[33] Tomalia, D.A. (2009) In Quest of a Systematic Framework for Unifying and Defining Nanoscience. Journal of Nanoparticle Research, 11, 1251-1310. https://doi.org/10.1007/s11051-009-9632-Z

[34] Lembo, D., Donalisio, M., Civra, A., Argenziano, M. and Cavalli, R. (2018) Nanomedicine Formulations for the Delivery of Antiviral Drugs: A Promising Solution for the Treatment of Viral Infections. Expert Opinion on Drug Delivery, 15, 93-114. https://doi.org/10.1080/17425247.2017.1360863

[35] Singh, L., Kruger, H.G., Maguire, G.E., Govender, T. and Parboosing, R. (2017) The Role of Nanotechnology in the Treatment of Viral Infections. Therapeutic Advances in Infectious Disease, 4, 105-131. https://doi.org/10.1177/2049936117713593

[36] Ben-Shabat, S., Yarmolinsky, L., Porat, D. and Dahan, A. (2020) Antiviral Effect of Phytochemicals from Medicinal Plants: Applications and Drug Delivery Strategies. Drug Delivery and Translational Research, 10, 354-367. https://doi.org/10.1007/s13346-019-00691-6

[37] Al-Halifa, S., Gauthier, L., Arpin, D., Bourgault, S. and Archambault, D. (2019) Nanoparticle-Based Vaccines against Respiratory Viruses. Frontiers in Immunology, 10, 22. https://doi.org/10.3389/fimmu.2019.00022

[38] Mokhtarzadeh, A., Eivazzadeh-Keihan, R., Pashazadeh, P., Hejazi, M., Gharaatifar, N., Hasanzadeh, M., Baradaran, B. and Guardia, M.D.L. (2017) Nanomaterial-Based Biosensors for Detection of a Pathogenic Virus. Trends in Analytical Chemistry, 97, 445-457. https://doi.org/10.1016/j.trac.2017.10.005

[39] Ludmila, K., Petr, M., Miguel, M.R., Zbynek, H., et al. (2015) Nanoscale Virus Biosensors: State of the Art. Nanobiosensors in Disease Diagnosis, 4, 47-66.

[40] Querido, M.M., Aguiar, L., Neves, P., Pereira, C.C. and Teixeira, J.P. (2019) Self- 
Disinfecting Surfaces and Infection Control. Colloids and Surfaces B: Biointerfaces, 1, 8-21. https://doi.org/10.1016/j.colsurfb.2019.02.009

[41] Geyer, F., D’Acunzi, M., Aghili, A.S., et al. (2020) When and How Self-Cleaning of Superhydrophobic Surfaces Works. Science Advances, 6, eaaw9727.

[42] Dalawai, S.P., Aly, M.A.S., Latthe, S.S., Xing, R., Sutar, R.S., Nagappan, S., Ha, C.-S., Sadasivuni, K.K. and Liu, S. (2019) Recent Advances in the Durability of Superhydrophobic Self-Cleaning Technology: A Critical Review. Progress in Organic Coatings, 138, Article ID: 105381. https://doi.org/10.1016/j.porgcoat.2019.105381

[43] Dyshlyuk, L., Babich, O., Ivanova, S., Vasilchenco, N., Prosekov, A. and Sukhikh, S. (2020) Suspensions of Metal Nanoparticles as a Basis for the Protection of Internal Surfaces of Building Structures from Biodegradation. Case Studies in Construction Materials, 12, e00319. https://doi.org/10.1016/j.cscm.2019.e00319

[44] Rai, M., Deshmukh, S.D., Ingle, A.P., Gupta, I.R., Galdiero, M. and Galdiero, S. (2014) Metal Nanoparticles: The Protective Nano Shield against Virus Infection. Critical Reviews in Microbiology, 42, 46-56. https://doi.org/10.3109/1040841X.2013.879849

[45] Vaze, N., Pyrgiotakis, G., McDevitt, J., Mena, L., Melo, A., Bedugnis, A., Kobzik, L., Eleftheriadou, M. and Demokritou, P. (2019) Inactivation of Common HospitalAcquired Pathogens on Surfaces and in the Air Utilizing Engineered Water Nanostructures (EWNS) Based Nano-Sanitizers. Nanomedicine, 18, 234-242. https://doi.org/10.1016/j.nano.2019.03.003

[46] Ren, G., Oxford, J.S., Reip, P.W., Lambkin-Williams, R. and Mann, A. (2013) Anti-Viral Formulations Nanomaterials and Nanoparticles. United States Patent 2013/009 1611 A1.

[47] Yetisen, A.K., Qu, H., Manbachi, A., Butt, H., Dokmeci, M.R., Hinestroza, J.P., Skorobogatiy, M., Khademhosseini, A. and Yun, S.H. (2016) Nanotechnology in Textiles. ACS Nano, 10, 3042-3068. https://doi.org/10.1021/acsnano.5b08176

[48] Spagnol, C., Fragal, E.H., Pereira, A.G.B., Nakamura, C.V., Muniz, E.C., Follmann, H.D.M., Silva, R. and Rubira, A.F. (2018) Cellulose Nanowhiskers Decorated with Silver Nanoparticles as an Additive to Antibacterial Polymers Membranes Fabricated by Electrospinning. Journal of Colloid and Interface Science, 531, 705-715. https://doi.org/10.1016/j.jcis.2018.07.096

[49] Mansi, A., Boccuni, F. and Iavicoli, S. (2019) Nanomaterials as a New Opportunity for Protecting Workers from Biological Risk. Industrial Health, 57, 668-675.

https://doi.org/10.2486/indhealth.2018-0197

[50] El-Nahal, I.M., Salem, J., Anbar, R., Kodeh, F.S. and Elmanama, A. (2020) Preparation and Antimicrobial Activity of ZnO-NPs Coated Cotton/Starch and Their Functionalized $\mathrm{ZnO}-\mathrm{Ag} /$ Cotton and $\mathrm{Zn}$ (II) Curcumin/Cotton Materials. Scientific Reports, 10, Article No. 5410. https://doi.org/10.1038/s41598-020-65025-w

[51] Srinivas, A.D., Peng, C., Mittal, A.C. and Agarwal, P. (2018) Surfaces Having Particles and Related Methods. United States Patent 10024840B2. 